\title{
Institutional Consequentialism and Global Governance
}

\begin{abstract}
Elsewhere we have responded to the so-called demandingness objection to consequentialism - that consequentialism is excessively demanding and is therefore unacceptable as a moral theory - by introducing the theoretical position we call institutional consequentialism. This is a consequentialist view that, however, requires institutional systems, and not individuals, to follow the consequentialist principle. In this paper, we first introduce and explain the theory of institutional consequentialism and the main reasons that support it. In the remainder of the paper, we turn to the global dimension where the first and foremost challenge is to explain how institutional consequentialism can deal with unsolved global problems such as poverty, war and climate change. In response, following the general idea of institutional consequentialism, we draw up three alternative routes: relying on existing national, transnational and supranational institutions; promoting gradual institutional reform; and advocating radical changes to the status quo. We evaluate these routes by describing normatively relevant properties of the existing global institutional system, as well as by showing what institutional consequentialism can say about alternatives to it: a world government; and multi-layered sovereignty/neo-medieval system.
\end{abstract}

Keywords. consequentialism; institutions; global justice; institutional consequentialism; global governance; world government; neo-medievalism; state

\section{Introduction}

Consequentialist morality, by requiring us to do what is best from an impartial point of view, imposes obligations on individuals that can be very demanding. Can this morality be so demanding that we have reason not to follow its dictates? According to many, it can. Elsewhere $^{1}$ we take the plausibility and coherence of this objection - the demandingness objection - as a given and put forward a response that we think has not received sufficient attention in the literature: institutional consequentialism. This is a consequentialist view that requires institutional systems, and not individuals, to follow the consequentialist principle. In the present paper, we approach institutional consequentialism from a different angle. We first introduce our account as a theoretical framework to respond to global challenges, in particular, global poverty, climate change, and the threat of (nuclear) war (section II). We then provide general reasons in favour of institutional consequentialism other than its ability to respond to the demandingness problematic. First, the basic institutional structure consisting of legal and

\footnotetext{
${ }^{1}$ See (retracted for blind review). Others, consequentialists as well as non-consequentialists, have also noted this ability of institutions. See, for a non-consequentialist such position, Nussbaum (2006), pp. 309-310.
} 
political systems, as well as economic institutions, can make the necessary background adjustment that individuals cannot and should not be expected to make (section III). Second, institutions determine the content of consequentialist morality for individual agents: they coordinate the collective pursuit of consequentialist goals when individual duties cannot be specified without prior institutional assignment (section IV). After this, we spend a section (V) on working out the most plausible form of institutional consequentialism. We come down on the side of a two-level version of institutional consequentialism that distinguishes the actconsequentialist criterion of rightness applied to the conduct of institutions from the decisionprocedures individuals, both private citizens and public officials, have to follow. Finally (section VI), we ask the question: how can the theoretical framework of institutional consequentialism respond to global challenges? We frame our discussion by contrasting the status quo (including the state system and supranational institutions) with radical options such as a neo-medieval global order and the world state. We discuss several reasons in favour of pursuing gradual reforms of the status quo (section VII) but we also mention the questions they leave open (section VIII). We then end the paper with a brief summary and concluding remarks (section IX).

\section{Institutional Consequentialism}

Our world is plagued by problems - such as global poverty, the threat of nuclear war, and climate change - that call for global action. For example, around 760 million people living in extreme poverty cannot afford a "minimum nutritionally adequate diet and essential non-food requirements". ${ }^{2}$ Largely as a result of this poverty, millions - including 6 million children under 5 - die each year. The suffering and premature death of millions of people due to hunger and preventable diseases is morally bad. The prevention of these deaths and suffering would make

\footnotetext{
${ }^{2}$ For details see UN Millennium Development Goals Report (2015); World Bank (2016); Pogge (2007: 2).
} 
the world a better place. And so would, of course, eliminating or at least mitigating the effects of climate change as well as putting an end to nuclear proliferation and reducing, if not eliminating the threat of war.

We take it that advocates of every moral theory can agree on at least some of these descriptively grounded normative claims. This includes the doctrine that we focus on in this paper: consequentialism. In its most influential, act-consequentialist, version this theory holds that whether an act is morally right, depends only on the valuable consequences of that act. ${ }^{3}$ More precisely, in its classical form which we will not question in this paper, promotion is understood as maximization. Thus, its single principle, often called the principle of beneficence, gives us the act-consequentialist criterion of rightness: "act in such a way as to produce the best possible consequences." On this criterion, to turn back to our example, the affluent have a duty to alleviate global poverty, regardless of whether beneficiaries are citizens of the same country. In general, there is a compelling moral reason to promote humanitarian projects until the point when doing so would do more harm than good, since all lives are of equal moral worth from an impartial perspective. ${ }^{4}$

However, consequentialism, including act-consequentialism, comes in many shapes and sizes. Elsewhere, as noted in the introduction, we defend an institutional version of consequentialism that we think is superior to other forms of consequentialism at least in one respect: the way it handles the so-called demandingness objection. ${ }^{5}$ Institutional consequentialism - as we call it - builds on an influential idea of an avowedly nonconsequentialist thinker: John Rawls's (1971) theory of justice. Adapting his point about social justice to consequentialist morality, we hold that the following division of labour is justifiable:

\footnotetext{
${ }^{3}$ For a good overview of consequentialism, see Sinnott-Armstrong (2015).

${ }^{4}$ The obvious reference point here is the classic argument in Singer (1972).

${ }^{5}$ See (retracted for blind review). The objection is built upon two pillars: one, that consequentialism is excessively demanding and, two, that an adequate morality shouldn't be excessively demanding. For an early statement, see Sidgwick (1907), p. 87; for a recent discussion, see Cullity (2004), Chapter 1.
} 
the consequentialist principle regulates the design of a basic institutional structure, whereas individuals have the duty to set up and maintain these institutions. ${ }^{6}$

Regarding an institution as a public system of rules which defines institutional roles with rights and duties attached to them (cf. North 1990: 3), our focus will be on the institutions of what Rawls (1999: 47-8, 55) has called the basic structure comprising legal and political systems, and economic institutions. ${ }^{7}$ There are good reasons supporting institutional consequentialism which are compatible with the consequentialist goal and are not rooted in the independent moral status of non-consequentialist values. First, as Rawls emphasizes, the basic institutional structure of society can make the necessary background adjustment that individuals cannot and should not be expected to make. Second, institutions often determine the content of consequentialist morality for individual agents: they coordinate the collective pursuit of consequentialist goals when individual duties cannot be specified without prior institutional assignment. In the following two sections, we spell out these two ideas in more detail.

\section{Institutions and background adjustment}

Institutions enable agents to act on local, often partial, reasons rather than to aim at consequentialist ends. In particular, they contribute to the more effective promotion of consequentialist goals by counteracting informational, cognitive and motivational limitations

\footnotetext{
${ }^{6}$ The term "ethical division of labour" comes from Nagel (1979). See also Nagel (1991) for a more detailed - but non-consequentialist - investigation of this Rawlsian thought.

${ }^{7}$ In particular, this basic structure includes roughly "the political constitution and principal economic and social arrangements". It covers legal rules affecting property and the organization of the economy. Property is determined not only by property law regimes but by a broader set of public norms including contract and commercial law, laws in criminal law against force and fraud, public health law, labour regulations etc. See Rawls (1993: 258, 282-3). There is, of course, more to be said about what institutions are; we do this in (retracted for blind review). What is important for us in this paper is that this view of institutions is compatible with consequentialism, which, we think, it is. Compare the utilitarian position on institutions in Bailey (1997) and Hardin (1988) for a proof.
} 
in individual agents. ${ }^{8}$ They are also necessary for a division of labour allowing individual agents to specialize and exploit their comparative advantages. We take up each consideration in turn.

Consider, first, the point that institutions are better placed to deal with the consequences of individual choices that run far into the future and spread across a large number of individuals. Markets notably have the virtue of coordinating decentralized information. They can structure competition among agents with limited information to generate efficient outcomes. For instance, entrepreneurs do not know the willingness to pay of all their potential customers, or the reservation wages of potential employees. Thus, economic actors lack crucial information they would need if they were to calculate the social costs and benefits of their options, e.g. in the range of potential prices they can set for their products or in the range of salaries they could pay to their employees. Furthermore, the consequences of our actions lead into the indefinite future, and we have imperfect knowledge about how they will affect future persons.

Not only do we not currently have all relevant information about the consequences of our actions, it is also undesirable for us to try to maximize the information available to us. Due to our cognitive limitations collecting and processing information is costly (think of the notion of bounded rationality put forward by March and Simon (1958)). Individual agents are unlikely to maximize the good by spending all their time gathering information and trying to calculate the consequences of all the available courses of action open to them. Market institutions allow agents to economize on information by consulting market prices. This is a standard theme in the writings of economists. As Hayek (1976: 20) famously put it ${ }^{9}$ : the trouble with the

\footnotetext{
${ }^{8}$ Hardin (1988: 6-9) discusses another type of limit of reason: limitations concerning our value theory. The idea is that we are limited in assessing both utility to ourselves as well as utility to others. These limits have partly to do with the difficulties concerning interpersonal comparisons of value and with the possible non-additivity of value (such as the case of organic wholes).

${ }^{9}$ Hayek, the economist, that is, not Hayek, the political philosopher: we are not suggesting that our position would somehow be in line with Hayek's general libertarian political theory.
} 
utilitarian approach is that it neglects to take account of our ignorance. With the help of institutions, this shortcoming is at least mediated, if not entirely overcome.

Next, individual agents' capacity to promote the good is further compromised by their tendency to biases such as self-deception due to non-consequentialist motives (Smart 1956: 347). Institutions correct for these biases by removing informational and motivational burdens from individuals in their day-to-day decisions.

Finally, institutions allow for an efficient division of labour between agents with different skill-sets and opportunity costs. They are necessary for a specialization that exploits agents' comparative advantages. Take the example of adversarial systems such as legal procedures which are often justified by pointing out that a division of labour between adversaries leads to the best outcomes. Defenders are required - within the limits of law - to do what they can in order to get their client acquitted even when they know them to be guilty. The necessary division of labour - adversary or otherwise - is likely to involve experts with special skills or knowledge and the assignment of special responsibilities, powers and prerogatives to participants.

The idea of background adjustment is that the consequentialist goal can be more effectively promoted in an institutional setting involving a division of labour than by independent individual actions by agents each of whom aims at promoting the good. This division of labour permits and may even require some agents to act on partial rather than impartial reasons following, for example, self-interest in markets and the interests of principals in courts of justice. Agents are to follow a narrow range of reasons in day-to-day decisions rather than aiming at promoting consequentialist goals. The upshot of these considerations is that the institutional structure can make the necessary background adjustment that individuals cannot and should not be expected to make. 


\section{Institutions constituting moral content}

Besides replacing a broader set of factors agents are to consider with a narrower one, the division of labour under consideration specifies the content of consequentialist morality for individual agents when individual duties are indeterminate. Institutional rules allocate responsibilities within a larger group. To take two examples, political and economic institutions coordinate the behaviour of large numbers of agents in strategic settings, and they solve collective action problems and implement policies that would otherwise not be implemented. Again, we discuss each in turn.

Consider first institutional coordination in a strategic setting. The outcome associated with individual choices often depends on the choices of numerous other agents which are in turn influenced by expectations about what the former might do. Owing to this kind of strategic interaction there is often no way to determine in the absence of institutions what course of action one ought to do in pursuit of consequentialist goals (Hardin 1988). Institutional rules are an effective means to coordinate strategic interaction such that a group of individuals can achieve a morally optimal outcome when this is possible only if everyone or a sufficiently large number of people follow the same course. For example, institutional systems single out one specific combination of property rules, welfare provisions, educational and health systems etc. from among several possible combinations that are equally desirable on consequentialist grounds since they produce equivalent outcomes (Miklósi 2008; Miklós 2011). Political institutions thus specify underdetermined consequentialist demands by settling a unique set of rules.

In addition to their coordinating function, political institutions solve collective action problems and implement beneficial policies that would otherwise not be implemented. For example, institutions are needed to provide public goods such as clean air or population 
immunity against infectious diseases. ${ }^{10}$ The provision of these goods requires the joint contribution of a significant part of the population. However, individuals have an incentive not to contribute their share since they benefit regardless and they find contribution costly. ${ }^{11}$ Institutional rules involving sanctions against noncompliance and positive incentives encouraging contribution counteract the incentive to free-ride and to make public goods possible. They provide assurance to members of a group that others contribute their share of the collective burden.

Institutional rules allocate responsibilities within the larger group in an authoritative manner since it is not at all obvious who bears what responsibility in promoting the good. How institutions go about allocating responsibilities is partly a matter of devising the most efficient division of labour (given individual preferences, comparative advantages etc.) but there is also an element of arbitrariness in dividing up the tasks. This is clearest in the case of public good provision, where individual contributions make no real difference to the outcome once the good - e.g. population immunity - is there. ${ }^{12}$

We want to emphasize that institutions are subject to different rules when they coordinate, allocate and enforce responsibilities among their participants than the participants themselves. Institutional rules sometimes pre-empt the application of consequentialist reasoning by their subjects and permit or even require reliance on partial considerations, as in the case of economic competition or adversarial systems. Finally, at the extreme, as in the cases of public good provision and perfectly competitive market equilibria, individual duties do not even make sense without prior institutional assignment since by assumption individual actions

\footnotetext{
${ }^{10}$ Public goods are defined as goods that are non-excludable and non-rivalrous. That is, no one within the relevant population can be excluded from their benefits and their consumption by one person does not reduce the quantity or quality available for others.

${ }^{11}$ For a discussion of the case of vaccinations in this context, see Miklós (2009).

${ }^{12}$ A further way in which economic and political institutions assign responsibilities in a constitutive manner is by determining distributive shares through an authoritative determination of property rights. See Miklós (2011).
} 
make no difference to the outcomes. In short, consequentialist goals can sometimes be only collectively interpreted (Regan 1980: 186).

\section{The best version of institutional consequentialism}

We hope that the above considerations suffice to make at least a provisional case for institutional consequentialism. ${ }^{13}$ Assuming that this is so, we will now spend some time on clarifying the exact nature of institutional consequentialism. ${ }^{14}$

Our preferred version keeps the original act-consequentialist setting and connects it to the Rawlsian division of labour idea. We think this is best done by endorsing a version of twolevel consequentialism. ${ }^{15}$ That is, institutional consequentialism makes use of the well-known distinction between criterion of rightness and decision-procedure: the former is still given by (maximizing) act-consequentialism, but the latter consists mostly (but not exclusively) in decision procedures that common-sense morality recognizes - they are those decision-making rules the following of which produce the best consequences overall. ${ }^{16}$ Now, for reasons given in previous sections, for individuals perhaps the most important such decision rule is to set up

\footnotetext{
${ }^{13}$ As noted at the start of this paper, elsewhere (retracted for blind review) we argue that another reason to endorse institutional consequentialism is that it tackles the demandingness objection. Its ability to do so, however, is in part dependent on the considerations discussed in the previous two sections. In particular, we argue for three points. First, institutions reduce consequentialist demands on individuals by restricting individual contributions to the moral cause to the setting up and maintaining of institutions. Second, institutions economize on the time and attention spent by individuals on the pursuit of consequentialist goals. Third, institutions also remove some of the motivational burdens in making and executing decisions. We also respond to objections to these claims: that institutional consequentialism merely transfers the demandingness problematic to the institutional level and that even if maintaining an institution is not objectionably demanding, setting up institutions is. Finally, using in part the considerations we will discuss as favouring gradual global institutional reforms, we consider how institutional consequentialism can handle the demandingness objection on the global level.

${ }^{14}$ Our approach differs both from classical consequentialism and from the Rawls-inspired existing global justice literature. Although consequentialism - or, more precisely, utilitarianism - was born as a theory that targets institutional reforms, it is, in its classical form, a monistic theory: the same principles apply to institutions as to individuals. By contrast, institutional consequentialism is a pluralistic theory, and it thus differs markedly from classical consequentialism. Cf. Berkey (2016) and Murphy (1998) for opposing views. On the other hand, much of the existing global justice literature is overwhelmingly focused on institutions, as both sources of justice requirements and agents of justice, however, these theories endorse an institutional division of labour on Rawlsian - i.e., non-consequentialist - grounds. We thank an anonymous referee for raising this point.

${ }^{15}$ Goodin (1995: 61-2), Bailey (1997: 24-7), Hardin (1988: 14-7, 100-110) seem to agree, although their use of the term "rule-consequentialism" is ambiguous between two readings. The same is true of Mulgan (2007: 126-8).

${ }^{16}$ For classic statements of such positions, see Hare (1981); Railton (1984).
} 
and maintain institutions that are designed according to the act consequentialist principle of beneficence. ${ }^{17}$ In short, while the criterion of rightness is the same both for individuals and for institutions, the former are not necessarily required to apply the principle of beneficence in their every-day conduct. ${ }^{18}$

However, as it stands, this view is not complete. Institutions, recall, are public systems of rules. Hence it is these rules that are to be designed according to act-consequentialism. But notice also that at least some of these institutions are run by public officials and in the case of these institutions many of the traditional problems of act-consequentialism might reappear (Eggleston 2014: 136-7). In particular, as we saw earlier, act-consequentialism requires huge amounts of information regarding the consequences of actions, since it has to reckon with all the consequences of every possible action way out in the unforeseeable future. Although this could be, at least to some extent, counteracted by a division of labour among the officials themselves, decision-making could still be seriously crippled by all the information gathering, processing and constant calculation. Also, act-consequentialism might lead to the breaking down of coordination that we praised above as an advantage of institutional consequentialism. This is because the officials would expect one another not to stick to plans and commitments since, as committed act-consequentialists, they would shirk from these plans as soon as an opportunity with better (expected) consequences arose.

These problems count in favour of introducing decision procedures for public officials that are different from the principle of beneficence that inform the design of the rules that constitute the institutions. In other words, they push us to extend two-level consequentialism to institutional conduct as well insofar as this concerns individual decision-making within the

\footnotetext{
${ }^{17}$ We leave it open whether or not this rule belongs to common-sense morality and we also do not take side on the matter whether institutions, owing perhaps to the indeterminacy in what the act-consequentialist criterion of rightness requires, themselves would specify this rule for individuals.

${ }^{18}$ We are deliberately using tentative language here - "perhaps most important", "not necessarily" - since, as we explain below, a two-level consequentialist can never be sure that these decision rules are always the best ones to apply.
} 
institutions. Moreover, as Goodin (1995: 62-5) persuasively argues, these decision procedures should be general in form allowing only for few exceptions.

To sum up, as two-level institutional consequentialists, we hold that both private citizens and public officials, although their conduct is ultimately evaluated by an actconsequentialist criterion of rightness that is also used to design institutions, are to apply general rules that need not be consequentialist and hence need not be the same as the rules that constitute the institutions. For private citizens, the most important decision rule is to set up and maintain institutions; for public officials, there could be any number of rules, among them, especially perhaps on higher administrative levels, the principle of beneficence itself. A caveat is needed here, though. Two-level consequentialist rules are typically considered to be what Rawls (1955) calls "summary rules": heuristic devices, "rules of thumb" that are to be employed in decision-making only insofar as they do indeed produce the best consequences. If it turns out that they do not, the rules can be broken, an exception created or an entirely different rule employed. ${ }^{19}$ Since we have already admitted that public officials can use the principle of beneficence as a decision rule (albeit, we reckon, rarely), the question naturally arises whether the same is true of private citizens. Our response is that we indeed don't deny that private citizens might, on occasion, resort to directly applying the principle of beneficence but, for the reasons given in preceding sections, this would rarely happen, if at all. ${ }^{20}$

This is then our general picture of what institutional consequentialism should look like. Of course, many questions can be asked about our switch to institutions as well as about our specific version of institutional consequentialism. Elsewhere we discuss and respond to most

\footnotetext{
${ }^{19}$ We say "typically considered" because two-level consequentialists are not restricted to regarding all social rules as rules of thumb. They can support the adoption of legal rules and social practices that do not allow direct application of the consequentialist principle in particular cases. These rules may even penalize actions that do in fact maximize utility. Thus, another role of institutions in two-level consequentialism is to modify behaviour by changing payoffs and preferences.

${ }^{20}$ How rare these occasions would be, depends on whether the rule to set up and maintain institutions would be part of an ideal (understood as involving conditions of full compliance) or a non-ideal set of decision rules. In the former case, following the rule (jointly, we presume, with other rules) would produce extensional equivalence with the requirements of act-consequentialism; in the latter case, it wouldn't.
} 
of these. Here, given our focus on global matters, there is only one issue we would like to address to further clarify our position. It could be claimed that by endorsing two-level consequentialism we are only paying lip service to the idea of a division of labour since, strictly speaking, we do not have different moral principles for individuals and for institutions. Instead, we have the same moral principle, i.e., the same criterion of rightness, but different decision rules. Our answer to this is to bite the bullet: we do not see why this must be a problem. It is clear that we have a division of labour in place, albeit it is not one that would introduce a rupture into the structure of consequentialism. It would have to be a rupture, it seems, since, on the proposed alternative that is now demanded of us, there would have to be two more codes, one for individuals and one for institutions, and only the latter would be consequentialist. Although "consequentialism" is often considered to be a family resemblance term, such a hybrid theory would be stretching things too far. ${ }^{21}$

\section{Institutional consequentialism and global challenges}

Institutional consequentialism is well supported by the above considerations. Is it useful, though, when it comes to addressing pressing global challenges such as poverty, peace and climate change? If so, what are its implications for the global institutional system?

On the face of it, the institutional approach appears to be in trouble here since it seems that, in contrast with domestic problems and institutions, the relevant institutions, but not the problems, are missing on the global domain.

\footnotetext{
${ }^{21}$ Nonetheless, we keep an open mind on these matters. There are two ways to go: either abandon the actconsequentialist criterion of rightness or keep it but abandon two-level consequentialism. As to the first, interesting candidates could be Regan's (1980) co-operative utilitarianism or Mendola's (2006) multiple-act consequentialism. Although we personally are not in favour of it, a switch to some kind of rule-consequentialism is also possible. Alternatively, but along similar "indirect" lines, we could abandon standard act-consequentialism, and instead adopt a view that only applies consequentialism to questions about the right institutions, then going on to evaluate acts indirectly (e.g. the right act is the one that is required by the best institutions, and/or that makes the biggest positive contribution to bringing and about and/or sustaining the best institutions). As to the second approach, one option would be this: by the lights of act-consequentialism itself, individuals' most pressing or important moral obligations concern their contributions to the establishment and upkeep of institutions because it so happens that the most effective ways for individuals to do good proceed via individuals' effects on institutions.
} 
One reply to this objection is to endorse an extreme version of what is often called the relationist position in the literature on global justice: that moral claims are grounded in certain institutional relations among people. ${ }^{22}$ Hence the response: since these relations do not exist globally, there are no global moral requirements either. However, we are not inclined to endorse this way of thinking about global morality; besides, and this is more important in the present context, consequentialism is the prime example of a non-relationalist theory, i.e. one that does not ground moral claims in institutional relations among people. ${ }^{23}$

If we don't go down this path, we must find the relevant institutions. There are several, not mutually exclusive, ways to proceed. One is to point out that there are already several global institutions that can be used for the purposes of fulfilling consequentialist requirements. ${ }^{24}$ The status quo includes nation-states and a system of supranational institutions, and as we shall argue below, this enhanced nation-state system is the necessary point of departure for a consequentialist response to global challenges. Next, this enhanced nation-state system could be reformed in order to better tackle challenges the current system has not been able to effectively deal with. Finally, rather than advocating for the reform of particular, relatively constrained institutions, consequentialists could make a radical break with the status quo. One alternative is to promote the establishment of a global state; another is to endorse a system of overlapping authorities and multiple loyalties in which nation states, along with regions, cities and other units, are only one participant among many (the position often referred

\footnotetext{
${ }^{22}$ Relationists hold that a necessary condition for requirements of distributive justice to exist among individuals is that the latter stand in specific practice-mediated relations with one another. One representative of this view is Nagel (2005). Note, however, that relationists about global justice allow for the existence of humanitarian moral obligations outside these relationships.

${ }^{23}$ Some, like Nagel (2005), seem to hold that a non-relational theory must be monist (i.e., the same principles must apply to individuals as to institutions), but we fail to see the connection. The relational/non-relational distinction concerns the grounds of normative claims against others (with consequences for their scope), whereas the monism/dualism distinction is about the site of these claims (i.e., where these principles apply: individuals, institutions, or both). Although both invoke institutions, they do so in an entirely different role.

${ }^{24}$ This strategy coincides with proposals by relationist advocates of global justice. For an early representative see Pogge (1994); for a more recent one see, Moellendorf (2011). Of course, the justification for their proposals differs from the consequentialist position we started out with, since they hold that claims of justice are grounded in institutional relations.
} 
to as neo-medievalism). ${ }^{25}$ In what follows we briefly evaluate, from a consequentialist point of view, these alternatives.

\section{The status quo: the (extended) state system}

Although we cannot do justice here to the vast body of existing research on institutions and governance, we can at least indicate some of the relevant institutions. Begin with the most obvious of these: nation-states. Consequentialists can regard the state-system as a set of distributed general obligations (Goodin 1988: 685). Each government bears a special responsibility for its citizens' welfare since it is better to have a system of states each of which is responsible for a limited number of people than to require everyone to be responsible for everyone else - recall our previous discussion of the benefits of specialization, division of labour and coordination. This institutionally governed system of assigned responsibilities in turn reduces the burdens on individuals.

Furthermore, given that we have a system of nation-states, governments are in general in a better position to promote the welfare of their citizens than outside actors are. The institutional stance in the development economics literature emphasizes the quality of institutions as the primary determinant of economic development within countries. Outside actors can at best help the global poor by providing assistance in building institutions, for example by facilitating analytical work, supporting reform initiatives and providing technical assistance, rather than by sending direct aid to improve welfare. For this reason, Risse (2012: $68-69,80)$ argues that duties to provide international assistance are sometimes going to be less demanding than might be thought or no duty will apply since what needs to be done cannot be done by outsiders.

\footnotetext{
${ }^{25}$ This list is not exhaustive. Part III of Bull (1995) discusses further alternatives; however, and we agree, he discards them as unable to solve global problems, which is our primary concern here.
} 
Nation-states are not the only relevant institutions, however. States are embedded in a system of transnational institutions such as the WTO, the IMF or the World Bank. Institutional consequentialists can welcome this fact since nation-states alone would not be able to solve global collective action problems such as providing effective protection during global public health emergencies or the prevention of a global 'race to the bottom' in labour regulations and tax laws. Nor can they satisfactorily specify duties for agents in domains such as international trade since it is often unclear which jurisdiction applies to them.

Transnational institutions can in some cases effectively coordinate national policies, solve global collective action problems, and specify duties for multiple agents. Relying on their authority to make, interpret, and enforce rules in direct or indirect rule-making relationships with individuals globally, transnational institutions fundamentally shape national policies and individual conduct by imposing sanctions and providing incentives in domains such as public health, food safety and product standards, labour standards and environmental regulation (Cohen and Sabel 2006: 165). They are at least potentially capable of performing the functions we argued require an institutional version of consequentialism.

Consider how global institutions such as the World Health Organization (WHO) can help solve global collective action problems arising between states as agents. Freedom from drug-resistant strains of infectious diseases such as tuberculosis is a global public good whose provision depends on transnational cooperation to overcome incentives for states to free-ride. Owing to the authority granted to the WHO by the current International Health Regulations to take action in public health emergencies even against resistance by member states, it can effectively combat infectious diseases globally. It can enforce compliance to policies that benefit all parties and provide assurance that other states will contribute their share to the provision and maintenance of the public good (Selgelid 2008). 
Fighting drug resistant diseases is one area where global institutions can help solve global collective action problems in public health, but it is not the only one. Another important example is the worldwide regime of intellectual property rights that incentivizes pharmaceutical innovation by giving innovator firms temporary monopoly over newly developed drugs. The global regulation of pharmaceutical patents governed by the TRIPs agreement allows innovators to recover high $\mathrm{R} \& \mathrm{D}$ and other costs that would be prohibitive in a market with no patent protection (Pogge 2010: 136-137). Through regulating intellectual property rights in the pharmaceutical industry, the TRIPs regime contributes to solving a global collective action problem that would characterise markets lacking similar safeguards protecting intellectual property.

The TRIPs agreement is part of the global trade regime governed by the World Trade Organization (WTO), but the mandate of WTO is broader than incentivizing pharmaceutical innovation. WTO promotes free trade and sets the framework for competition in global markets. Its rule based framework, relying on a capacity to impose sanctions, counteracts the temptation for governments to engage in protectionist policies and reduces the likelihood of a global protectionist race to the bottom. The institutionally regulated coordination within the WTO framework fosters competitive global markets and helps markets to better allocate resources through the price mechanism. Equally importantly, the global division of labour that regulated international trade makes possible helps the global poor escape poverty (Deaton 2013: 322-323). The WTO regime - though not perfect - is preferable to an alternative where bilateral trade treaties systematically disadvantage poor countries which lack the resources (e.g., money; know-how; expertise) to defend their economic interests under pressure from rich-country governments.

The global economic order is governed by a set of institutions - the Bretton Woods system - that were set up in the wake of World War II in order to promote global prosperity 
and peace. Besides the WTO, constituents of this economic framework include the World Bank and the International Monetary Fund, which are embedded in the UN-based global institutional system. This global order was designed with the intention to prevent war, to protect human rights, to promote social and economic development, and to protect the environment, among other objectives. Even though arguably it has been more successful in some domains than in others, the global institutional order is structurally suited to the institutional consequentialism we advocate. Many of its constituent national and supranational institutions are set up with specific - functionally limited - tasks in their mandate. Even in cases when objectives are less clearly defined - most importantly, in the case of nation-states - territorially limited jurisdictions facilitate a division of labour across countries that makes the consequentialist task more tractable.

Our current institutional world order including the state system as well as supranational institutions supports at least the beginnings of a consequentialist division of labour between individuals and institutions with different functions and jurisdictions. Institutions defining global trade regimes - such as the WTO - carry out the background adjustment necessary to overcome individual informational and cognitive limitations. Nation-states and functionally defined supranational institutions - such as the WHO, the World Bank and other UN-agencies - make possible the exploitation of the benefits of specialization in a worldwide functional and territorial division of labour. Finally, in areas such as global public health and trade, supranational institutions facilitate the implementation of globally beneficial policies by overcoming collective action problems.

Some of the consequentialist tasks will remain. Arguably, many of the currently existing institutions with a global impact are not optimal by consequentialist standards. For example, critics regard the current global intellectual property right regime governed by the TRIPs agreement under WTO jurisdiction as suboptimal (Pogge 2010: 136-153). It is better 
than providing no protection to innovator pharmaceutical firms since it incentivizes the development of new drugs by allowing firms to recoup their large investments into pharmaceutical R\&D. However, critics argue, the current system leads to a neglect of diseases typically afflicting the poor and concentrates resources on new drugs marginally improving the life-prospects of people living in affluent countries. A lot more benefit could be generated by some alternative institutional schemes - such as the Health Impact Fund or Advance Market Commitments - that incentivize the development of drugs for diseases afflicting the globally worst-off (Pogge 2010: 148-153).

Besides access to essential medicines, additional global problems in search of institutional solutions include climate change, poverty, corporate tax competition, and corruption. What is common to these unsolved problems is that they require collective action that often depends on institutional coordination, compliance enforcement and assurance. Reforming the current global institutional structure requires political action by individuals as well as by governments, political parties, firms and NGOs.

\section{Going beyond the status quo: gradual change vs. radical alternatives}

Consequentialists searching for ways to improve on the status quo have two options open to them. They can advocate for piecemeal reforms of the current global institutional setup, or they can promote radical change. Radical proposals differ in their answer to the question whether the traditional idea of state sovereignty should be discarded. Whereas a world state could retain all the features of sovereign states in the nation state system, only to encompass the entire world under its sovereignty (e.g. Tännsjö 2008), other institutional frameworks could abandon some features while retaining others. ${ }^{26}$ One example of such a proposal is Thomas Pogge's idea of

\footnotetext{
${ }^{26}$ Simon Caney (2005: 149-150) helpfully describes the system of sovereign states as possessing four defining features: legality; supremacy; territoriality; and comprehensiveness. Legality refers to states' authority over their jurisdiction. Supremacy indicates that this authority is final and absolute - with no other final and absolute authority over the same jurisdiction elsewhere. Territoriality refers to the fact that authority is defined over a
} 
multi-layered sovereignty with a vertical dispersal of authority, which would abandon supremacy (and perhaps comprehensiveness) as a feature of governance (Pogge 2008). In Pogge's scheme, persons could be citizens of several political units at the same time "without any one political unit being dominant and thus occupying the traditional role of the state" (Pogge 2008: 184). Another idea - of which multi-layered sovereignty can perhaps be considered a sub-case - is neo-medievalism (Zielonka 2006, 2014; the term was introduced by Bull 1995: 245). Neo-medievalism, as the term suggests, models institutional systems on the medieval past characterised by overlapping authorities (vs. concentration of power), divided and horizontal sovereignty (vs. hierarchy), multiple identities (vs. clear-cut identity) and fuzzy borders (vs. fixed and hard external borders), to name some contrasting points to the state system. The neo-medieval institutional system thus goes both ways: down (to localities, regions) and up (to the trans- and supra-national level), endorsing multiple identities, among them possible global commitments. ${ }^{27}$

Both multi-layered sovereignty/neo-medievalism and proposals for a world state call for a radical rethinking of what the world could look like, however. In fact, of the above outlined options of gradual institutional change versus radical break with the status quo, the former seems somewhat more promising on the basis of evidence from social scientific research. Here are three considerations, of admittedly varying strength, to support this claim. While the first argument is not (overtly) consequentialist, the second is, and the third poses a challenge that is particularly relevant for consequentialists given their reliance on strong epistemic presuppositions. (All this comes with a caveat, though. It is possible that global

territorially specified unit. Finally, comprehensiveness means that sovereign states have authority over all issues, not just some. Without trying to determine whether or not the world's current institutional setup can still be described as a system of sovereign states, we think that this is a useful conceptual framework for thinking about alternative institutional configurations.

${ }^{27}$ We are aware that more should be said of neo-medievalism given the relative unfamiliarity of the position to most theorists. However, this paper, given its space limitations, is not the right forum for such in-depth discussion. We must ask the reader to turn to the writings of Zielonka (in particular) for a comprehensive analysis. 
institutional configurations quite different from the status quo can be reached through a sequence of piecemeal reforms. In other words, the transition leading to a world radically different from ours does not necessarily involve radical steps along the way.)

The first point in favour of gradual change is that often the most effective way to promote institutional change is through the establishment of procedural rules. One reason why some transnational institutions are suboptimal is that they lack support or legitimacy. Institutions need to be shaped so that they motivate their own support (creating what Rawls calls stability for good reasons). Achieving this is not trivial since there are moral disagreements, including disagreements about socioeconomic justice, within any society, and disagreements are even more pronounced on the global level. It is to a large extent these disagreements that make the collective pursuit of consequentialist aims motivationally demanding. They generate collective action problems and obstruct coordination.

Establishing procedural requirements on decision-making may be a good way to achieve legitimacy and thus to reduce motivational demands individuals face. For instance, transnational institutions can be reformed to include in their decision-making frameworks those impacted by them in a way that the affected parties perceive as fair or legitimate (Rawls (1999) is one such attempt). Furthermore, institutional mechanisms may need to be installed to accommodate competing moral views or values. Since the current system of global institutions does not constitute a global democratic state, standard majoritarian democratic mechanisms are not available at the global level. Nonetheless, there are feasible alternative mechanisms that do not require a global democracy. What Daniels (2008) has termed Accountability for Reasonableness in the distribution of health care is a good example of a mechanism that can generate legitimacy without a full-blown majoritarian political decision-process on the global level. In short, although a world state that takes the form of a global democracy maybe a viable 
theoretical alternative, we might be able to achieve the required result without radical - hence: costly - breaks with what we have already built up on the global level. ${ }^{28}$

Consider the example of international aid that has failed to reduce poverty and promote development to a sufficient extent. Arguably, a major hindrance to achieving these goals in the face of large aid flows has been a bias towards donor interests, stemming from insufficient accountability and transparency in the decision-making processes of agencies such as the World Bank and the United Nations Development Programme (Deaton 2013: 274-277; 313). International aid effectiveness could be enhanced by improving accountability and transparency in the decision-making processes: for example, by better inclusion of the intended recipients - in particular against the interests of their corrupt governments who have been the main beneficiaries of international aid.

Second, the consequentialist argument can be made that when the pursuit of gradual reforms through legitimate procedures is not feasible - since there are no workable institutions in place or current institutions are perceived as grossly unjust or illegitimate - individuals likely have no consequentialist duty to fight for institutional reform since global collective action problems make individual attempts at system change futile and wasteful. Given the high likelihood that any such effort would merely be wasted, the expected utility of individual attempts at generating systemic change would be too little to ground any proper consequentialist obligation. ${ }^{29}$

\footnotetext{
${ }^{28}$ It is unclear that a neo-medieval global system would fare any better. Although Zielonka (2006: Chapter 1; 2014: Chapter 4) argues that his neo-medieval system can produce integration in the face of radical diversity and plurality and is able to produce democratic legitimacy, his focus is on Europe (the EU) solely. Hence the question whether and how his arguments can be extended to the global sphere, is left unanswered.

${ }^{29}$ This might seem too easy an exit: it neglects the possibility of change from below from real actors and real cases, such as those of Lech Walesa, Paul Farmer, Martin Luther King. These are people who might be thought of as exceptional but they do not come from exceptional backgrounds: they appear as exception only after the fact of their successful action. However, the problem is that the exceptionality of these individuals could well be understood in ethical terms: that what they did went beyond the call of duty, that is, it was supererogatory. Then what we would have to end up with at this point is the vexed matter whether (institutional) consequentialism has place for the supererogatory - a classic objection to consequentialism being that it has no such room. We would like to steer clear of this dispute in the paper and leave discussion of this objection to another occasion, however. We thank Eric Palmer for pointing out this challenge to us.
} 
Although this argument supports gradual reforms against radical change, the end result of the reform process is not clear-cut. As noted before, it is conceivable that a series of reforms will result in a global institutional architecture significantly different from the current one. For example, Pogge $(1992: 58,63)$ argues that multi-layered sovereignty can be reached gradually from where we are now through "second-order decentralization". More generally, some argue that most of the "ingredients" of the neo-medieval system are already in place and many existing international tendencies in the world point in this direction. Thus, Zielonka (2014; 2006 Chapter 8) argues that the EU is clearly moving in the direction of a neo-medieval 'empire' while others point to existing regulations that have a neo-medieval touch to them (Deets 2006) and that the global digital world economy is already heading in this direction (Kobrin 1999).

In the case of world government, the original argument - concerning the futility of transition and hence the voiding of consequentialist obligations to bring about the desire system - has more bite given how the world presently is. It has to be noted, though, that much depends on how one pictures the transition to world government. The more negative voices tend to see world government as coming about after a major catastrophe (e.g. Pogge 1992: 63) or after conquest, both of which would play in the hands of the objection above. And though it is conceivable that world government is established by contract, i.e., as a result of one great political effort of bringing states together, Bull (1995: 252-3) points out that this option suffers from the problem that such a contract would have to take place in international anarchy (as the state system is often characterized) where a contract without authority would be worth nothing. Yet, some argue that establishing a world government can also be achieved gradually on a step by step basis (e.g. Yunker (2012)'s idea of evolutionary world government). It might also come about indirectly, as an unintended consequence of several subsequent steps (a bit like the present EU). However, the more tenuous the link between the present global order and the 
world state becomes, the less compelling a case we find for a consequentialist duty for individuals to promote change in the direction of a world state now.

The third argument against proposals for radical change has an epistemic basis, hence it is particularly relevant for consequentialists given their strong epistemic requirements. Risse (2012: 315-21) argues that it is impossible to have a reasonably clear understanding of what a world completely different from our own - such as a world state or a world without states would look like. Not only do such utopias involve a radical uncertainty about future states of the world in which the probability distribution is unclear; there is also a breakdown of imagination in which it is impossible to even imagine what outcomes probabilities attach to. ${ }^{30}$ Owing to this incomplete understanding of alternative futures, counterfactual outcomes are impossible to evaluate. Risse makes the very strong claim that, under such conditions, advocating alternative institutional frameworks is immoral because it is irresponsible, given the potential significant or even devastating consequences, to bring about such systems. ${ }^{31} \mathrm{We}$ need not accept his strong conclusion in order to see that radical proposals indeed are problematic from a consequentialist perspective. Action-guiding consequentialist requirements must be based on an assessment of what can be achieved, given existing institutions, at what cost. The epistemic limits of utopias Risse talks about raise the justificatory burden radical institutional proposals face.

Risse's conclusion is sweeping; according to him, epistemic caution rules out all institutional alternatives that do not conform to his (Rawlsian) notion of a realistic utopia. In particular, any acceptable institutional scheme would have to be such that we can connect it to

\footnotetext{
${ }^{30}$ Bull (1995: 275, 280-1) makes at points similar claims. He says that the comparison of alternative utopias is a sterile and fruitless exercise: whether, e.g., the world state would produce global peace is something we have as much reason to assume to happen as we have to assume the same about the state system. His point appears to be that these are utopias so removed from reality that we cannot theorize about them fruitfully.

${ }^{31}$ His example with Marxism is telling (Risse 2012: 315-7). The Marxist utopia gave us a picture of the future. But we simply couldn't predict and imagine what that future in all relevant detail would look like once the basic ideas were implemented. Namely, hidden structural features came to the fore and had devastating effects. We could not predict this not only because we couldn't tell how likely this was to happen but also because we could not picture what would happen.
} 
our present world and our present thinking, which we could then use to extrapolate from to imagine the desired institutional set-up. ${ }^{32}$ However, there are at least two reasons why epistemic reasons need not rule out theorizing about alternative global orders.

First, Risse fails to show that a world state or a neo-medieval system would indeed involve such a radical departure from our reality that makes modelling them impossible. For this reason, it does not follow that a comparative evaluation of alternative institutional schemes is impossible. In order to evaluate the desirability of various institutional alternatives as aims we should aspire towards, further research is needed to determine whether a world state would really be radically different from existing supra- and transnational structures, and whether the new framework would require motivations radically different from what we can attribute to people today. The neo-medieval system might fare even better in this regard. It is, after all, modelled on the medieval past and, although we should not directly extrapolate, we may arguably have enough information to produce a clear enough picture that can serve as a "realistic utopia" for us. Whether we can use the medieval system as a theoretical model for evaluating the proposed neo-medieval system depends to a large extent on how close the latter would be to the former.

Second, when it comes to evaluating the paths towards institutional ideals (in Rawlsian parlance, non-ideal theory as opposed to ideal theory involved in selecting an institutional system to aspire towards), we should remember that radically different institutional structures can come about through piecemeal changes through time. The gradual approximation towards institutional ideals need not involve radical breaks with potentially devastating consequences Risse warns us about.

\footnotetext{
${ }^{32}$ According to Risse (2012: 322), the notion of realistic utopia has three parts. One, a realistic utopia is always relative to a time, and our age involves global structures based on states but nothing beyond that. Two, a realistic utopia reconciles us with our social world: there are some aspects of this world that we cannot or shouldn't change. Three, a realistic utopia must be such that what it recommends can be the subject of reasonable agreement among people and, apparently, radical institutional alternatives cannot fulfil this role. For a good overview of criticisms of the Rawlsian notion of realistic utopia, see Simmons (2010). For clear contrast, see Cohen (2008), Sen (2009).
} 


\section{Summary and concluding remarks}

The aim of this essay was twofold. We first introduced a version of consequentialism that we think has solid foundations. Institutional consequentialism, as we call it, requires that individuals promote the establishment of institutions that can solve global collective action problems and can specify and enforce duties for agents. This form of consequentialism thus calls for a division of labour between individuals and institutions - globally as well as domestically. Of course, our present world is far from perfect: New institutions need to be built, existing institutions need to be reformed, on both levels. Our next aim was, therefore, to see how institutional consequentialism can contribute to a better understanding of existing proposals for global change. Although identifying the most effective way to improve existing institutions in the current global framework is largely an empirical matter, we have tried to at least provide some framework to this discussion by setting out the available options - extended state system, world state, multi-layered sovereignty/neo-medievalism - and evaluating them according to certain criteria. Our discussion has shown that there are at least three reasons that might favour the enhanced state system (the status quo), but that "might" is an important qualifier in this statement. For there are also responses available to advocates of more radical alternatives and a final evaluation, therefore, would require more empirical as well as theoretical research and discussion. ${ }^{33}$

\footnotetext{
${ }^{33}$ Comprehensive discussion of this subject, we think, would require evaluating the possible institutional alternatives according to three criteria: desirability (is the given system desirable intrinsically or instrumentally?), necessity (is the given system one that we need to achieve important aims of ours?), and possibility (is it realistic, possible, or conceivable that the given system will come about?) The best, perhaps, is to see this discussion as giving us a picture in terms of a balance of reasons (provided by these three criteria) and that alternative system "wins" which is, on balance, supported by these reasons. Seen in this light, what we have done in this paper is to provide and assess some of these reasons - in particular, in the possibility and necessity dimension - but we have of course not provided a comprehensive discussion of all the reasons in all dimensions.
} 


\section{References}

Bailey, J. W. (1997), Utilitarianism, Institutions, and Justice. Oxford: Oxford University Press. Berkey, B. (2016), "Against Rawlsian Institutionalism about Justice." Social Theory and Practice 43 (4): 706-732

Bull, H. (1995), The Anarchical Society: A Study of Order in World Politics, $2^{\text {nd }}$ ed. New York: Columbia University Press.

Caney, S. (2005), Justice Beyond Borders: A Global Political Theory. Oxford: Oxford University Press.

Cohen, G. A. (2008), Rescuing Justice and Equality. Cambridge, Mass.: Harvard University Press.

Cohen, J. and Sabel, C. (2006), "Extra Republicam Nulla Justitia?" Philosophy and Public Affairs 34 (2): 147-175.

Cullity, G. (2004), The Moral Demands of Affluence. Oxford: Clarendon Press.

Daniels, N. (2008), Just Health. Cambridge: Cambridge University Press.

Deaton, A. (2013), The Great Escape: Health, Wealth, and the Origins of Inequality, Princeton: Princeton University Press.

Deets, S. (2006), "Pulling Back from Neo-medievalism: The Domestic and International Politics of the Hungarian Status Law." In Ieda, O. (ed.), Beyond Sovereignty: From Status Law to Transnational Citizenship?, Sapporo: Slavic Research Center, Hokkaido University, pp. 1737.

Eggleston, B. (2014), “Act Utilitarianism.” In. B. Eggleston and D. Miller (eds.), The Cambridge Companion to Utilitarianism. Cambridge: Cambridge University Press, pp. 124145.

Goodin, R. (1988), Reasons for Welfare: The Political Theory of the Welfare State. Princeton: Princeton University Press.

Goodin, R. (1995), Utilitarianism as a Public Philosophy. Cambridge: Cambridge University Press.

Hardin, R. (1988), Morality Within the Limits of Reason. Chicago, Ill.: University of Chicago Press.

Hare, R. M. (1981). Moral Thinking. Oxford: Clarendon Press.

Hayek, F. A. (1976), Law, Legislation and Liberty: A New Statement of the Liberal Principles of Justice and Political Economy, Volume II. The Mirage of Social Justice. Chicago, Ill.: University of Chicago Press.

Kobrin, S. J. (1999), "Back to the Future: Neomedievalism and the Postmodern Digital World Economy." In A. Prakash and J. Hart (eds.), Globalization and Governance, London: Routledge, pp. 165-188.

March, J. G. and Simon, H. A. (1958), Organizations. London: Wiley-Blackwell.

Mendola, J. (2006), Goodness and Justice. Cambridge: Cambridge University Press.

Miklós, A (2009), "Public Health and the Rights of States." Public Health Ethics 2 (20): 158170.

Miklós, A (2011), “The Basic Structure and the Principles of Justice." Utilitas 23 (2): 161-182. Miklósi, Z. (2008), "Compliance with Just Institutions." Social Theory and Practice 34 (2): 183-207.

Moellendorf, D. (2011), “Cosmopolitanism and Compatriot Duties." The Monist 94 (4): 535554.

Mulgan, T. (2007), Understanding Utilitarianism. London: Acumen.

Murphy, L. D. (1998), "Institutions and the Demands of Justice." Philosophy and Public Affairs, 27 (4): 251-291 
Nagel, T. (1979), "Ruthlessness in Public Life.” In Mortal Questions, Cambridge: Cambridge University Press, pp. 75-91.

Nagel, T. (1991), Equality and Partiality. New York: Oxford University Press.

Nagel, T. (2005), “The Problem of Global Justice." Philosophy and Public Affairs 33 (2): $113-$ 147.

North, D. (1990), Institutions, Institutional Change, and Economic Performance, Cambridge: Cambridge University Press.

Nussbaum, M. (2006), Frontiers of Justice: Disability, Nationality, Species Membership, Cambridge, Mass.: Harvard University Press

Pogge, T. (1992), "Cosmopolitanism and Sovereignty." Ethics 103: 48-75.

Pogge, T. (1994), “An Egalitarian Law of Peoples.” Philosophy and Public Affairs 23 (3): 195224.

Pogge, T. (2007), "Introduction." In T. Pogge, (ed.) Freedom from Poverty as a Human Right. Oxford: Oxford University Press, pp.1-10

Pogge, T. (2008), World Poverty and Human Rights, $2^{\text {nd }}$ ed., Cambridge; Polity Press.

Pogge, T. (2010), "The Health Impact Fund: Better Pharmaceutical Innovations at Much Lower Prices.” In T. Pogge, M. Rimmer and K. Rubenstein (eds.): Incentives for Global Public Health: Patent Law and Access to Essential Medicines. Cambridge: Cambridge University Press, pp. 135-154.

Railton, P. (1984) "Alienation, Consequentialism, and the Demands of Morality." Philosophy and Public Affairs 13: 134-171.

Rawls, J. (1955), “Two Concepts of Rules.” Philosophical Review 64 (1): 3-32.

Rawls, J. (1971), A Theory of Justice. Cambridge, MA: Harvard University Press.

Rawls, J. (1993), Political Liberalism. New York: Columbia University Press.

Rawls, J. (1999), The Law of Peoples. Cambridge MA: Harvard University Press.

Regan, D. (1980), Utilitarianism and Cooperation. Oxford: Clarendon Press.

Risse, M. (2012), On Global Justice. Princeton: Princeton University Press.

Selgelid, M. (2008), "Ethics, Tuberculosis and Globalization." Public Health Ethics 1: 10-20.

Sen, A. (2009), The Idea of Justice, Cambridge, Mass.: Harvard University Press.

Sidgwick, H. (1907), The Methods of Ethics, 7th ed. London: Macmillan.

Simmons, A. J. (2010), "Ideal and Nonideal Theory." Philosophy and Public Affairs 38 (1): 536.

Singer, P. (1972), "Famine, Affluence, and Morality." Philosophy and Public Affairs 1 (3): 229-43.

Sinnott-Armstrong, W. (2015), "Consequentialism." The Stanford Encyclopaedia of Philosophy (Winter 2015 Edition), Edward N. Zalta (ed.), URL = $<$ https://plato.stanford.edu/archives/win2015/entries/consequentialism/>.

Smart, J. J. C. (1956), "Extreme and Restricted Utilitarianism.” Philosophical Quarterly 6 (25): 344-354.

Tännsjö, T. (2008), Global Democracy: The Case for a World Government. Edinburgh: Edinburgh University Press.

UN Millennium Development Goals (2015), The Millennium Development Goals Report 2015. $\mathrm{URL}=\mathrm{http}: / / \mathrm{www}$.un.org/millenniumgoals/mdgnews.shtml

World Bank (2016), Poverty and Shared Prosperity: Taking on Inequality. URL = http://www.worldbank.org/en/publication/poverty-and-shared-prosperity (

Yunker, J. A. (2012), "Evolutionary World Government." The Canadian Journal of Peace and Conflict Studies 44 (1): 96-126.

Zielonka, J. (2006), Europe as Empire: The Nature of the Enlarged European Union. Oxford: Oxford University Press.

Zielonka, J. (2014), Is the EU Doomed? London: Polity Press. 